\title{
Behavioral test systems in marmoset monkeys
}

\author{
I. H. C. H. M. PHILIPPENS and B. P. C. MELCHERS \\ TNO Pharma, Rijswijk, The Netherlands \\ T. A. P. ROELING \\ Free University of Amsterdam, Amsterdam, The Netherlands \\ and \\ P.L.B. BRUIJNZEEL \\ TNO Pharma, Rijswijk, The Netherlands
}

\begin{abstract}
A number of neurobehavioral methods have been developed to test behavior in marmoset monkeys. These test systems are (1) the bungalow test, which quantifies spontaneous explorative behavior, (2) the hand-eye coordination test, which tests a learned task of coordinated motor behavior, and (3) the fear-potentiated startle response, which tests and quantifies pathological anxiety manifested by a response of fright. The test systems are extensively discussed, and the value of these test systems is exemplified by applying them to neurological disorders to register disease activity and drug efficacy.
\end{abstract}

Apart from observational (ethological) methods for counting certain activities, few automated tests are available for testing behavior in marmosets. For this reason, we have developed three different, fully automated behavioral test systems.

1. The bungalow test. The levels of activity, alertness, and exploratory behavior play an important role in practically all measurements of animal behavior. Hence, a device by which the combined locomotor and exploratory activity can be automatically and quantitatively assessed has been developed (Wolthuis, Groen, \& Philippens, 1994; see Figure 1).

2. The hand-eye coordination test. In this test, alertness, reaction time, motor speed, and correct learned responses can be measured. For this task, an automated robot-guided apparatus using positive reinforcement as a motivating stimulus (small pieces of marshmallow) has been developed (Wolthuis, Groen, Busker, \& van Helden, 1995; see Figure 2).

3. The fear-potentiated startle response, to test and quantify the response of fright. The startle response is a sensitive method to determine how different neurotransmitter systems modulate sensorimotor activities (Davis, Gendelman, Tischler, \& Gendelman, 1982). The auditory startle reflex is a motor response that follows an intense sound stimulus. A conditioned fear potentiation of the startle response is seen when the startle reflex is elicited in the presence of a cue (vs. the absence of this cue). An example of this cue may be lights on or off, previously paired with a shock (see Figure 3).

B. P. C. Melchers passed away on January 12, 2000. The other authors thank him for his scientific contributions. Correspondence concerning this article should be addressed to I. H. C. H. M. Philippens, Department of Pharmacology, TNO Pharma, P.O. Box 45, 2280 AA Rijswijk, The Netherlands (e-mail: philippens@pml.tno.nl).
These tests are relatively unique and have been validated since their introduction. In addition, these methods have proven helpful in objectively quantifying the progression of induced disease (e.g., Parkinson's disease). Once disease has developed, these methods allow one to test drug efficacy. In this paper, the methods will be discussed, and their applications exemplified.

\section{METHOD}

\section{The Bungalow Test}

Apparatus. The apparatus consists of four horizontally placed nontransparent PVC boxes $(23 \times 23 \times 23 \mathrm{~cm})$ with a wire-mesh top, interconnected by six photocellguarded PVC tubes (inner diameter, $9.5 \mathrm{~cm}$ ). It resembles a four-room bungalow. Hence, the test was called the bungalow test (see Figure 1). The tubes are wide enough to allow the animal to move directly to each of the three other boxes. The boxes are placed in a square, and the distance (center to center) of each box to the adjacent ones is $43 \mathrm{~cm}$. Four lights are mounted on the closed ceiling of the apparatus, each one vertically $170 \mathrm{~cm}$ above the center of the bottom of one of the four boxes. The floors of the boxes are made of white plastic and reflect the light, which is registered by photocells mounted on each of the wire-mesh tops and linked to an IBMcompatible PC. The presence of a marmoset in a box is detected by means of the decrease in reflected light. Movements of the animal from one box to another are detected by means of its disappearance from one box and its appearance in another. The linked computer registers the different parameters, such as (1) the time spent and time intervals of the presence of the animals in each box, (2) the number of times that the animal switches from one box to another, and (3) from which box these switches take place. The motor activity is expressed 


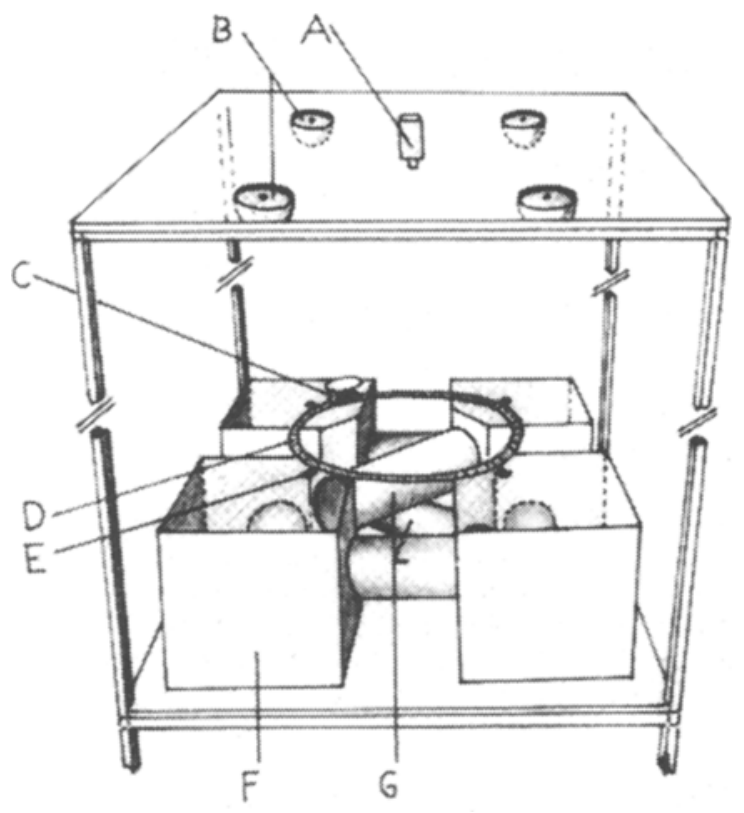

Figure 1. A drawing of the bungalow test apparatus. A, TV camera; $B$, lights; $C$, locomotive with disk for calibration of the test system; D, railroad; E, photocell; F, nontransparent box; G, interconnecting PVC tubes. The whole apparatus is surrounded by a nontransparent curtain (not drawn).

as the number of compartment changes in this time period.

A TV camera is mounted in the center of the ceiling, to allow observation of the animal. The whole apparatus is surrounded by a thick curtain, to avoid distraction of the animal.

Procedures. The marmoset can freely move and change from one compartment to the other during a 20 min session. Control measurements are performed twice; the results of the second control test are taken as the starting value for the animal. The exploratory activity does not drastically reduce upon repeated testing, resulting in a rather stable baseline, at least on four successive tests during 1 week (see Table 1). After the second test, the animals can be treated.

\section{The Hand-Eye Coordination Test}

Apparatus. A robot is situated behind a test panel provided with two windows $(8 \mathrm{~cm}$ wide and $5 \mathrm{~cm}$ high). These windows can open and close through a pneumatically driven and vertically sliding door. For the hand-eye coordination task, only the left window was used (see Figure 2). The test cage $(32.5 \times 24 \times 24 \mathrm{~cm})$ in which the marmoset is placed is situated in front of the test panel. The side of the test cage directly in front of the panel consists of horizontal stainless steel rods, spaced far enough apart to allow the animal to reach its arm at full length through the window. The robot holds an $8.5-\mathrm{cm}-$ long suction tube. For each trial, the robot turns to a plateau containing the rewards, sucks one reward onto the tip of the tube, and then moves it into the starting position behind the test panel. The presence of the reward at the tube is checked by a pressure detector that also registers the time needed for removal during the trial. A photocellmonitored trough on the inner side of the test panel registers the rewards that are not properly retrieved by the animal through the window into the test cage. Infrared detectors within the windows allow the registration of successful attempts of the animal to grasp a reward.

Procedure. The procedure for the hand-eye coordination test system has been described by Philippens et al. (2000). With this system, three types of trials are performed: one using a nonmoving reward in the middle of the window, one using a slow horizontally moving reward $(0.04 \mathrm{~m} / \mathrm{sec})$, and one using a fast-moving $(0.08 \mathrm{~m} /$ $\mathrm{sec}$ ) reward moving horizontally from the left to the right side of the window. The animal is allowed $1 \mathrm{~min}$ to grasp the nonmoving reward. Each type of trial is performed 14 times in one session. At the beginning of each trial, a sound signal is presented that is intended to alert the animal. Immediately thereafter, the window opens. At that point in time, the suction tube is in the ready position, in the nonmoving trials, or starts to move to the other position in the moving trials. A hit is registered when the animal successfully retrieves the reward from the suction tube. The numbers of attempts and failures are also registered. The percentage of correct hits is used as the criterion by which to judge the performance of the animal.

\section{The Auditory Startle Response}

Apparatus. The apparatus for measuring the startle response of marmoset monkeys (Melchers, Groen, Vanwersch, Philippens, \& Bruijnzeel, 1998) consists of a Plexiglas cylinder (diameter, $17.5 \mathrm{~cm}$; length, $26 \mathrm{~cm}$ ), closed at the top with a very fine wire mesh. This cylinder is connected with three pressure transducers that register the force exerted by the animal, while standing upright, upon presentation of the startle stimulus. The startle stimulus is a sound signal $(20 \mathrm{msec}, 120 \mathrm{~dB}$, white noise) generated by a PC, amplified using an Akai AM17 amplifier, and applied to the marmoset by a tweeter (piezo KSN 1086A, Telec, The Netherlands). The tweeter is placed $12 \mathrm{~cm}$ above the top of the Plexiglas cylinder. This whole system is placed in a sound-attenuated box of $42 \times 67 \times 70 \mathrm{~cm}$. The box may be illuminated with a 40-W light bulb. The output signal of the pressure transducers is amplified and filtered, using custom-built amplifiers/filters, and is fed into the analog-digital converter (ADC) in the PC (I/O card, PCL-812PG, Advantech Co.).

Procedures. The animals are exposed to auditory startle pulses while standing in the Plexiglas cylinder (see Figure 3). The number of startle stimuli that can be administered to the animals depends on the type of experiment conducted. The computer is programmed in such a way that sound stimuli can be delivered, in random order (i.e., at an interval of $20 \pm 4 \mathrm{sec}$ ), with different strengths and/or at different intervals. In addition, the PC controls the illumination (i.e., on or off) of the sound- 


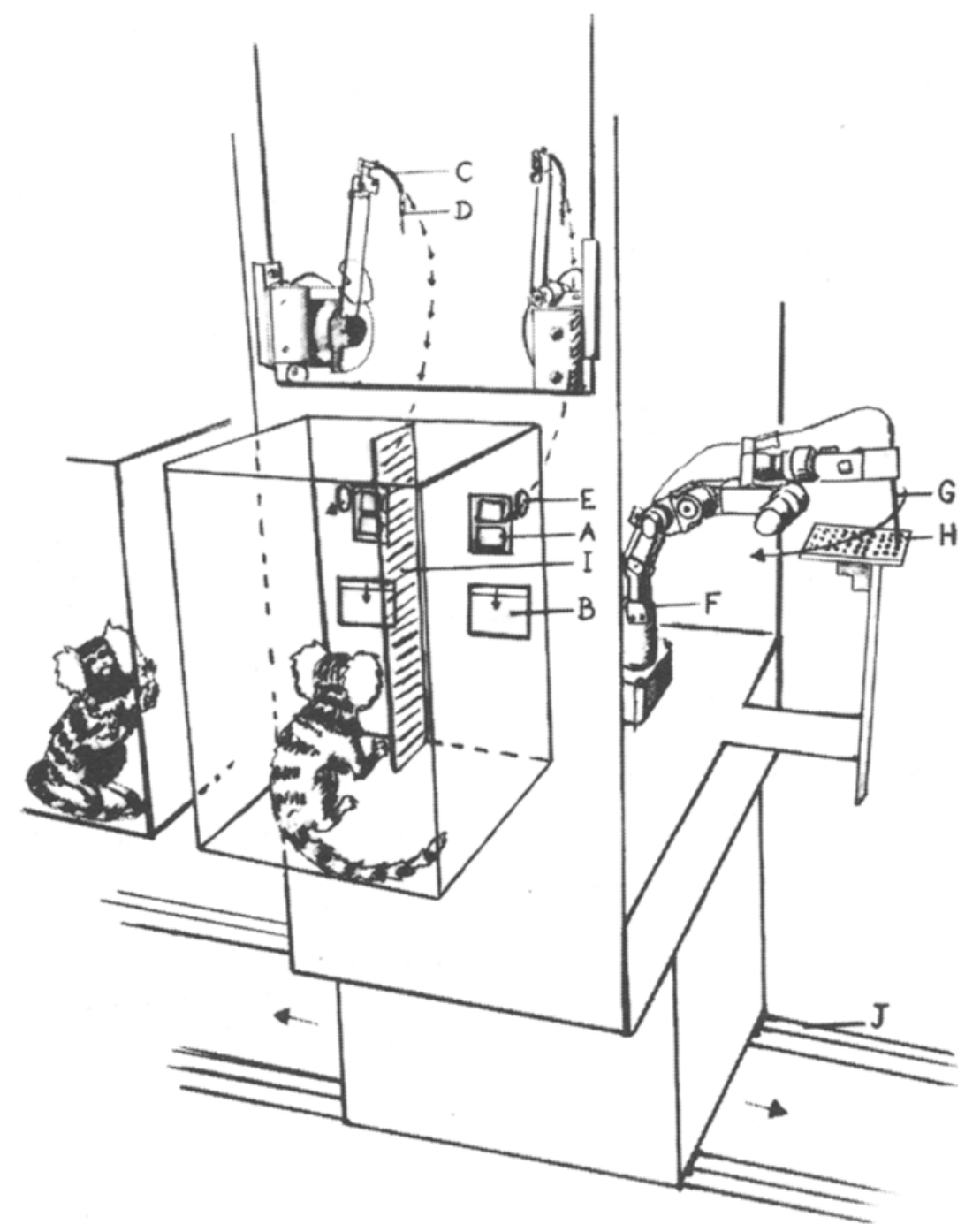

Figure 2. Schematic illustration of the robot-assisted behavioral test apparatus for measuring hand-eye coordination in marmoset monkeys motivated by positive reinforcement. A, numerical display; B, window; $C$, handles; D, small chain attached to the handle; $E$, holes through which the handles are introduced into the cage; F, robot arm; G, suction tube; $\mathbf{H}$, tray with marshmallow-like rewards; I, partition screen; $J$, rails.

attenuated box. To prevent large variations in the responses owing to movements of the animals unrelated to the startle stimulus, the stimuli are given only when the animal does not move. This is calibrated by the computer.

For the duration of $200 \mathrm{msec}$, the force exerted by the animal upon presentation of the stimulus was registered. The data were digitized $(50 \mathrm{~Hz})$ by the ADC of an IBMcompatible $\mathrm{PC}$, averaged, and stored on disk for later analysis. The amplitude and area under the curve (AUC) measured for the duration of $200 \mathrm{msec}$ after presentation of the startle pulse was used to measure the startle reflex.

\section{Animals}

Primates are our closest animal relatives. Therefore, intuitively, it appears that the chance that a monkey will react in a similar way to drugs as we do is much greater than that a rodent will do so. Indeed, neuro-anatomical studies show, for example, that there is more similarity in the regional distribution through the hippocampus of several neurotransmitter receptor types, including the 5HT1 receptor, in marmosets and humans than in rats and humans (Kraemer et al., 1995). Furthermore, dopaminergic projections to the hippocampus are much more dense in primates than in rodents (Samson, Wu, Friedman, \& Davis, 1990), and there appears to be a difference in the D4 receptor gene between primates (including humans and marmosets) and rats (Matsumoto, Hidaka, Tada, Tasaki, \& Yamaguchi, 1995). In addition, the distribution over the brain of D1 and D2 dopaminergic receptors may differ between rodents and primates (Camps, Kelly, \& 


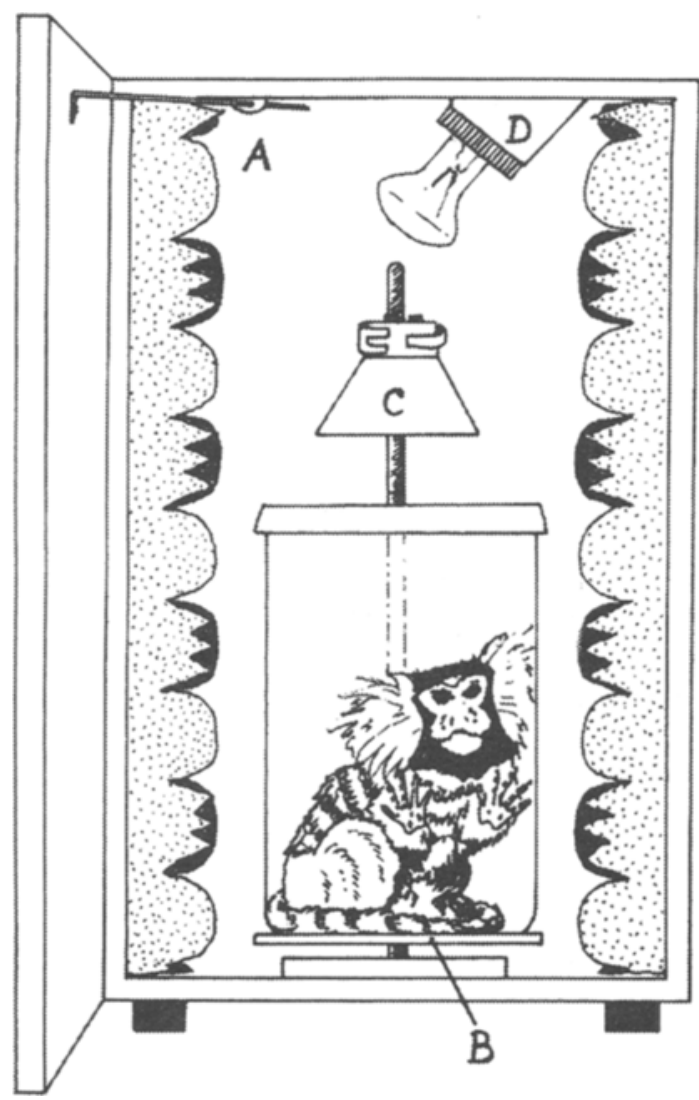

Figure 3. Startle system for marmosets. A, sound-attenuated chamber; $B$, the platform to which the pressure transducer recording the signal is connected; $C$, loudspeaker, used for application of both prepulse and startle stimuli; $D$, light bulb for the illumination of the chamber. For fear conditioning, the light was turned off.

Palacios, 1990; Meador-Woodruff, Mansour, Civelli, \& Watson, 1991).

Adult marmoset monkeys (Callithrix jacchus) of both sexes, bred and raised at the Biomedical Primate Research Centre (Rijswijk, The Netherlands), were used. The animals were housed separately in cages $(61 \times 61$ $\times 41 \mathrm{~cm}$ ) in a room kept at $23-25^{\circ} \mathrm{C}$ and at a relative humidity of $>60 \%$. In this room, a 12-h day and night cycle was maintained. Daily, they were fed with rice, peanuts, fruit, boiled egg, baby biscuits, sunflower seeds, honey, broad bean, Karvan cevitam, and pellet chow after training or testing. Water was available ad lib. The experiments described herein received prior approval by an independent ethical committee.

\section{Induction of Disease Models}

Parkinson's disease. In the MPTP model, animals are injected subcutaneously for 5 days with a solution of 1.75-mg MPTP in sterile saline. After these injections, the animals clearly develop Parkinsonian symptoms. Control animals receive saline at the same points in time (Jenner,
Rupniak, Rose, \& Kilpatrick, 1984; Pérez-Otaño et al., 1991).

In the 6-OHDA model, a unilateral depletion of the dopamine cells in the substantia nigra is induced (Apicella, Trouche, Nieoullon, Legallet, \& Dusticier, 1990; Roeling et al., 1995). This is achieved by three stereotactically placed injections of $1-\mu 16-O H D A$ solution $(16 \mathrm{mg} /$ $\mathrm{ml}$ in ascorbic acid) at the following coordinates: AP, 6.5; ML, 1.2; DV, 6.5; AP, 6.5; ML, 1.2; DV, 7.0; AP, 6.5; ML, $1.7 ; \mathrm{DV}, 7.0$ (cf. the atlas of Stephan, Baron, \& Schwerdtfeger, 1980).

\section{Statistical Measures}

All the data are expressed as a mean $\pm S E M$. For data showing just two responses, the (paired) Student's $t$ test is used. For data made up of more than two responses, a one-way analysis of variance (ANOVA) with a NewmanKeuls post hoc test or Friedman's ANOVA was followed, when significant, by a Dunn's multiple comparison test for testing of individual differences.

\section{RESULTS}

In the following, we will exemplify how the various neurobehavioural tests have been validated and can be used to reflect either disease activity or the efficacy of drugs in the marmoset monkey.

\section{The Bungalow Test}

Reproducibility of the test when measured at different occasions. When the number of compartment changes was measured on different days during 1 week, this test proved to be quite reproducible (see Table 1).

Drug effects. When two different drugs were tested that (1) stimulated spontaneous motor activity (methamphetamine) or (2) depressed spontaneous motor activity (pentobarbital), the results, as had been expected, were as shown in Figure 4.

Development of bilaterally induced Parkinson's disease by MPTP. Symptomatology from Parkinson's disease was closely parallelled by changes observed in the bungalow test. The akinesia that developed after intoxication with MPTP was significant. Seven days after injections with MPTP $(1.75 \mathrm{mg} / \mathrm{kg})$ had started, there was clinically significant akinesia. In the bungalow test, the number of compartment changes was reduced from $99.6 \%$ $\pm 32 \%$ to $5.3 \% \pm 3 \%($ mean $\pm S E M, n=6)$.

When full Parkinsonism had been induced (bilaterally), treatment with L-DOPA significantly increased spontaneous motor activity.

Table 1

Number of Compartment Changes $(n=6)$

\begin{tabular}{|c|c|c|c|c|c|c|c|}
\hline \multicolumn{8}{|c|}{ Day } \\
\hline \multicolumn{2}{|c|}{1} & \multicolumn{2}{|c|}{2} & \multicolumn{2}{|c|}{3} & \multicolumn{2}{|c|}{8} \\
\hline$M$ & $\pm S E M$ & $M$ & $\pm S E M$ & $M$ & $\pm S E M$ & $M$ & $\pm S E M$ \\
\hline 108 & 26 & 131 & 23 & 141 & 35 & 132 & 25 \\
\hline
\end{tabular}




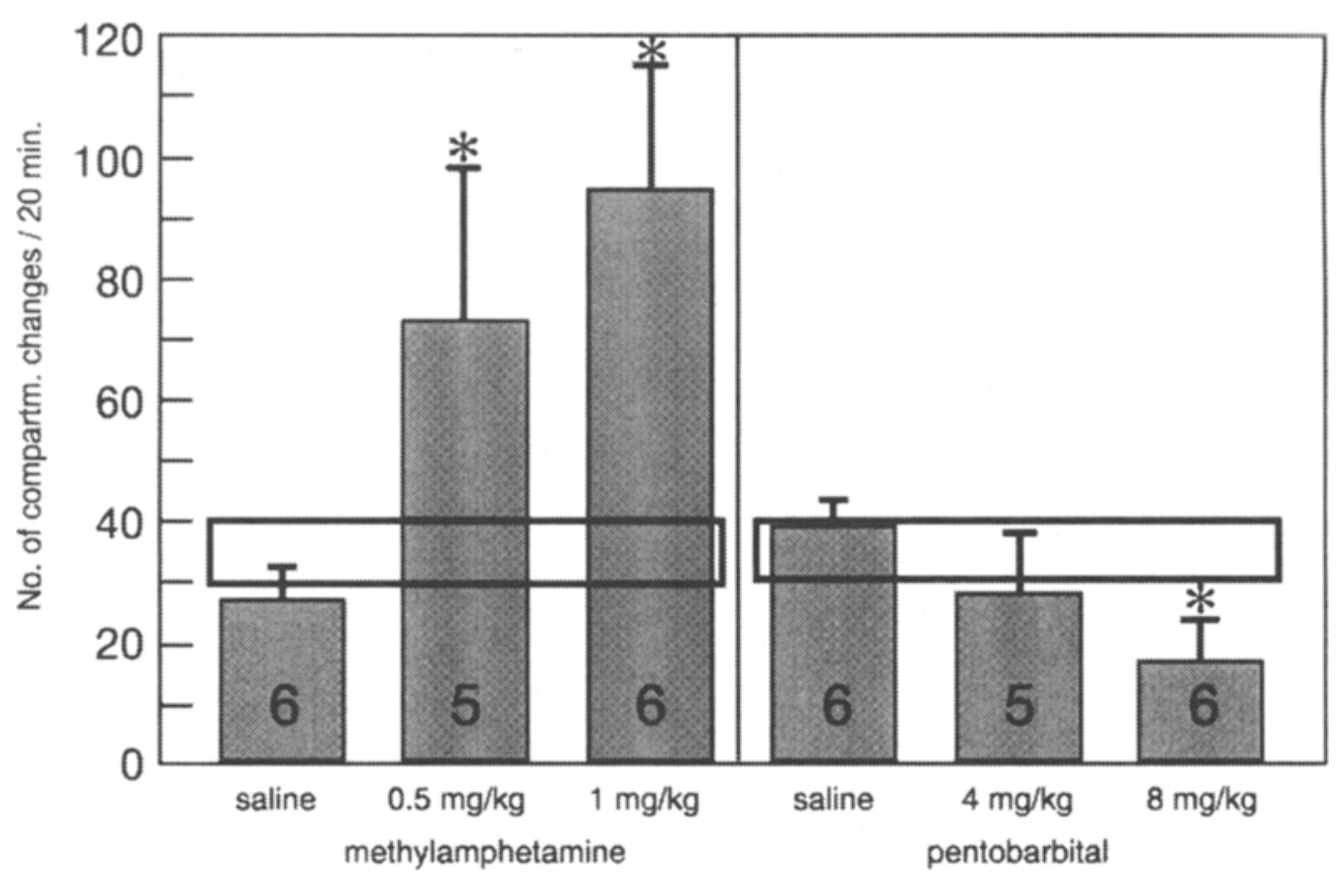

Figure 4. The effects of intramuscular methamphetamine and pentobarbital on the number of compartment changes. The tests with pentobarbital were conducted with the same animals, after a rest period of 14 days following the injections of methamphetamine. The horizontal bar represents the mean $( \pm S E M)$ control number of compartment changes tested on the day before the injections with each drug took place. *Significantly different from the effect of saline.

\section{The Hand-Eye Coordination Test}

Reproducibility of the test. When marmoset monkeys had been fully trained to retrieve the sweets properly, they normally retrieved about $80 \%-85 \%$ of the sweets. This test could be repeated with these monkeys on different occasions and appeared to be fully reproducible when tested on different occasions over an 8-day period (see Figure 5). Consecutive experiments have indicated that this reproducibility lasts for many weeks ( $>6$ weeks) and, therefore, can be used to evaluate objectively not only the development of the symptoms of brain intoxications or diseases, but also the effects of drugs that oppose those.

Development of bilaterally induced Parkinson's disease by MPTP. MPTP-induced Parkinsonism also affected the learned behavior/motor skill task, as reflected by the hand-eye coordination task. Parkinsonism significantly decreased the total number of retrieved sweets in the hand-eye coordination test (from $86.0 \% \pm 2.0 \%$ to $13.0 \% \pm 3 \%$; mean $\pm S E M, n=6 ; p<.0001$, Student's $t$ test). When saline instead of MPTP was injected, no changes were observed $(82.0 \% \pm 6.0 \%$ during the 1 st week and $81.0 \% \pm 7.0 \%$ during the 2 nd week).

Development of unilaterally induced Parkinson's disease by MPTP. A unilateral depletion of the dopaminergic stores could be achieved in the brain by directly injecting 6-OHDA. This affects the functioning of the motor activity of the contralateral hand, but not of the ipsilateral hand. A measure of efficiency of the functioning hand is the total number of retrieved sweets divided by the num- ber of attempts. In 5 monkeys, hand-eye coordination measurements were performed before, 9 days after, and 16 days after the 6-OHDA injection. Before the operation, the values were $78.0 \% \pm 7 \%$ (mean $\pm S E M, n=5)$ for the

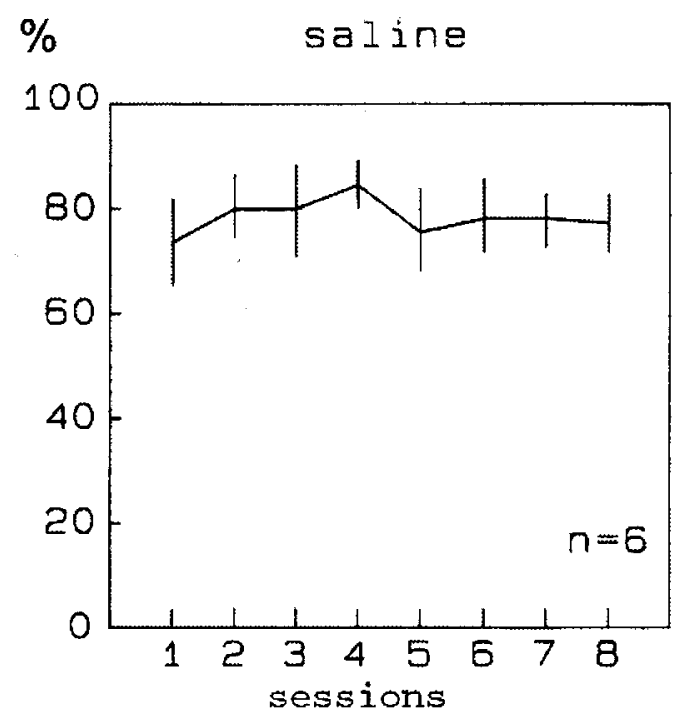

Figure 5 . The mean $( \pm S E M, n=6)$ of the percentage of correct responses in the hand-eye coordination task during 8 daily sessions (the weekend was between Sessions 5 and 6). After a training period of 5 weeks, testing began on Session 1. At Sessions 2 and 4, the animals were injected with a control treatment (saline, IM). 
contralateral hand and $59.2 \% \pm 8 \%$ for the ipsilateral hand. The functioning of the contralateral hand after the operation appeared to be significantly less $(26.6 \% \pm 8 \%)$ than that before the operation ( $p<.001$, Dunn's multiple comparison test after a Friedman test on ANOVA). For the ipsilateral hand, the value was $54.8 \% \pm 14 \%$ (not significantly different from control value). L-dopa $(10 \mathrm{mg} / \mathrm{kg}$, orally) was administered prior to the last test. As a consequence, the number of successfully retrieved sweets for the contralateral hand increased significantly to $52.4 \% \pm$ $15 \%$, whereas this number for the ipsilateral hand remained almost the same $(58.8 \% \pm 6 \%)$.

\section{Fear-Potentiated Startle Response}

Reproducibility of the test. There appeared to be a significant increase in the startle response when fear was induced: the lights-off situation, versus the lights-on situation, caused an increase in the response $(131.0 \pm 15$ vs. $78.4 \pm 4$ in AUC; $p<.02$, Student's $t$ test; $n=4$ ). This condition remained present and stable, provided that the animals were trained every week for a period of at least 18 weeks following the induction of the fear-potentiated startle response (see Table 2).

Drug effects. Once a situation of fear potentiation was established, this situation could be used to test anxiolytic drugs, such as diazepam. Diazepam showed a significant dose-dependent reduction of the fear potentiation, as is shown in Table 3.

\section{DISCUSSION}

In this paper, we have introduced several unique behavioral test methods for marmoset monkeys and have tried to indicate their value in monitoring induced disease states and in establishing drug efficacy. The behavioral models described herein consist of (1) a test of the spontaneous exploratory behavior of the monkey, called the bungalow test, (2) the hand-eye coordination test, reflecting the combination of a learned task with motor activity, and (3) the fear-potentiated startle response, reflecting a response of fright that is enforced by giving a cue (lights off). The bungalow test is a very reproducible test when a monkey is kept under normal, quiet conditions. There exists, however, a clear interindividual difference. Some monkeys are much more active than others, and for this reason, the results for groups need to be expressed

Table 2

The Mean $( \pm S E M)$ Level of the Fear-Potentiated Startle Response Expressed as a Percentage of the Baseline Startle Reflex Level (Without Fear) During Several Weeks

\begin{tabular}{ccc}
\hline & \multicolumn{2}{c}{ Level of Fear Potentiation } \\
\cline { 2 - 3 } Week & $M$ & $S E M$ \\
\hline 1 & 192 & \pm 43 \\
2 & 150 & \pm 24 \\
4 & 204 & \pm 77 \\
6 & 186 & \pm 51 \\
\hline
\end{tabular}

Table 3

The mean $( \pm S E M)$ Effects of Diazepam on the Fear-Potentiated Startle Response Expressed as a Percentage of the Baseline Startle Reflex Level (Without Fear)

\begin{tabular}{ccc} 
& \multicolumn{2}{c}{$\begin{array}{c}\text { Effect on Fear-Potentiated } \\
\text { Startle Response }\end{array}$} \\
\cline { 2 - 3 } Diazepam Dose $(\mathrm{mg} / \mathrm{kg})$ & $M$ & $S E M$ \\
\hline 0.0 & 201 & \pm 19 \\
0.3 & 137 & \pm 32 \\
1.0 & 107 & $\pm 20^{*}$ \\
3.0 & 108 & $\pm 15^{*}$ \\
\hline
\end{tabular}

Note- Diazepam was injected intramuscularly at the dose levels presented. ANOVA: $F(3,16)=3.67, p=.032, n=5 . \quad{ }^{*} p<.05$.

as a percentage, taking the original (basic) value of the monkey as the reference value (i.e., the $100 \%$ value). In case of the hand-eye coordination test, our experience is that 1 out of 8 monkeys is not able or motivated to learn to grasp the sweets from the robot within the training sessions and, for this reason, should not be included in the study. Although no data havc been shown in this paper, this test has been shown to be a very sensitive test for elucidating brain damage induced by toxicants. The third test, the fear-potentiated startle response, reflects pathological anxiety. Also, with this test, a prescreening of a group of animals has to be performed, since 1 out of 5 monkeys does not show a response of fright in this test and can, therefore, not be used in this test system. Furthermore, one needs to realize that one needs experienced personnel for handling this type of monkey, to be able to perform this test reproducibly. Also, the test facilities require special provisions.

The most relevant examples of the use of these test models originate not from toxicological studies, but from our experience with certain disease models and with the testing of drug efficacy in these models.

If one, for example, induces Parkinson's disease by injecting MPTP, the number of compartment changes in the bungalow test, as well as the number of correctly retrieved sweets in the hand-eye coordination test, will be reduced drastically in parallel with the induction of disease symptomatology. The akinesia present in these animals is reflected clearly by a lack of movements in the bungalow test; in addition, decreased motor coordination, such as that for hand use in the hand-eye coordination test, was also found by others (Apicella et al., 1990; Jenner et al., 1984; Pérez-Otaño et al., 1991; Roeling et al., 1995). In the latter test, the lack of efficient hand use, partly caused by the lack of reaction of the animals (a form of apathy) to the presentation of a sweet, adds to the observed decrease in the number of successfully retrieved sweets. This test may also be used to test the hand use function in a hemiparkinsonistic model, induced by 6-OHDA (Apicella et al., 1990). In this situation, the motivation of the animals to grasp a reward is not disturbed. However, they will preferentially use their ipsilateral hand, and this test indicates a defective functioning of the use of their 
contralateral hand. That this type of test could be of great practical importance when antistroke therapy has to be evaluated does not need further comment.

The fear-potentiated startle response in rats is normally used as one of the most important models for studying the efficacy of anxiolytic drugs (Hijzen, Houtzager, Joordens, Olivier, \& Slangen, 1995). Here, a primate model is proposed that is different from the "human threat" model (Costal et al., 1992). In our model, we induce fear in a way that is similar to that used with the rat (Hijzen et al., 1995), by applying a light footshock in combination with a cue (lights off). This system is capable of inducing a response of fright that, once induced, may last reproducibly for around 18 weeks. This is an ideal situation for various types of drug testing (single vs. repeated dose applications). As an example of the usefulness of this model, the effects of the anxiolyticum diazepam have been shown. Although we did not perform any statistical testing, because of the small number of monkeys used $(n=4)$, it is clearly shown that diazepam suppresses the fearpotentiated startle response in a dose-dependent manner.

In conclusion, we have been able to develop several behavioral test systems for the marmoset monkey that allow one to objectively, reproducibly, and quantitatively measure the severity of clinical symptoms of various neurological/psychiatric disorders. Moreover, they allow the objective evaluation of the efficacy of drugs for these disorders - in particular since, in these models, the clinical symptomatology remains stable long enough that repeated drug testing is possible.

\section{REFERENCES}

Apicella, P., Trouche, E., Nieoullon, A., Legallet, E., \& DusTICIER, N. (1990). Motor impairments and neurochemical changes after unilateral 6-hydroxydopamine lesion of the nigrostriatal dopaminergic system in monkeys. Neuroscience, 38, 655-666.

Camps, M., Kelly, P. H., \& Palacios, J. M. (1990). Autoradiographic localization of dopamine $D 1$ and D2 receptors in the brain of several mammalian species. Journal of Neural Transmission: General Section, 80, 105-127.

Costal, B., Domeney, A. M., Farre, A. J., Kelly, M. E., MarTINEZ, L., \& NAYLOR, R. J. (1992). Profile of action of a novel 5 -hydroxytryptamine $1 \mathrm{~A}$ receptor ligand $\mathrm{E}-442$ to inhibit aversive behavior in the mouse, rat and marmoset. Journal of Pharmacology \& Experimental Therapeutics, 262, 90-98.

Davis, M., Gendelman, D. S., Tischler, M. D., \& Gendelman, P. M. (1982). A primary acoustic startle circuit: Lesion and stimulation studies. Journal of Neuroscience, 2, 759-806.

Hijzen, T. H., Houtzager, S. W. J., Joordens, R. J. E., Olivier, B., \&
Slangen, J. L. (1995). Predictive validity of the potentiated startle response as a behavioral model for anxiolytic drugs. Psychopharmacology, 118, 150-154.

Jenner, P., Rupniak, M. J. P., Rose, S., \& Kilpatrick, G. (1984). 1-Methyl-4-phenyl-1,2,3,6-tetrahydropyridine induced Parkinsonism in the common marmoset. Neuroscience Letters, 50, 85-88.

Kraemer, M., Zilles, K., Schleicher, A., Gebhard, R., Robbins, T. W., EveritT, B. J., \& Divac, I. (1995). Quantitative receptor autoradiography of eight different transmitter-binding sites in the hippocampus of the common marmoset Callitthrix jacchus. Anatomy \& Embryology, 191, 213-225.

Matsumoto, M., Hidaka, K., Tada, S., TASaki, Y., \& Yamaguchi, T. (1995). Polymorphic tandem repeats in dopamine D4 receptor are spread over primate species. Biochemical \& Biophysical Research Communications, 207, 467-477.

Meador-Woodruff, J. H., Mansour, A., Civelli, O., \& Watson, S. J. (1991). Distribution of D2-dopaminergic receptor mRNA in the primate brain. Progress in Neuropsychopharmacology \& Biological Psychiatry, 15, 885-893.

Melchers, B. P. C., Groen, B., Vanwersch, R. A. P., Philippens, I. H. C. H. M., \& BruijnzeEL, P. L. B. (1998). Set-up of a system to reliably measure the startle response in marmoset monkeys: Application in animal models of anxiety and psychosis (TNO Report PML 1998-B42). Rijswijk, The Netherlands: TNO Prins Maurits Laboratorium.

Pérez-Otaño, I., Herrero, M. T., Oset, C., De Ceballos, M. L., Luquin, M. R., Obeso, J. A. \& Del Rio, J. (1991). Extensive loss of brain dopamine and serotonine induced by chronic administration of MPTP in the marmoset. Brain Research, 567, 127-131.

Philippens, I. H. C. H. M., Vanwersch, R. A. P., Groen, B., Olivier, B., Bruijnzeel, P. L. B., \& Melchers, B. P. C. (2000). Subchronic physostigmine pretreatment in marmosets: Absence of side effects and effective against soman poisoning with negligible post intoxication incapacitation. Toxicological Sciences, 53, 84-91.

Roeling, T. A. P., Docter, G. J., Voorn, P., Melchers, B. P. C., Wolters, E. C., \& Groenewegen, H. J. (1995). Effects of unilateral 6-hydroxydopamine lesions on neuropeptide immunoreactivity in the basal ganglia of the common marmoset, Callithrix jacchus. A quantitative immunohistochemical analysis. Journal of Chemical Neuroanatomy, $9,155-164$.

Samson, Y., Wu, J. J., Friedman, A. H., \& Davis, J. N. (1990). Catecholaminergic innervation of the hippocampus in the cynomolgous monkey. Journal of Comparative Neurology, 298, 250-263.

StePhan, H., Baron, G., \& SchwerdTfeger, W. K. (1980). The brain of the common marmoset (Callithrix jacchus): A stereotaxic atlas. Berlin: Springer-Verlag.

Wolthuis, O. L., Groen, B., Busker, R. W., \& van Helden, H. P. M. (1995). Effects of low doses of cholinesterase inhibitors on behavior performance of robot-tested marmosets. Pharmacology, Biochemistry \& Behaviour, 51, 443-456.

Wolthuis, O. L., Groen, B., \& Philippens, I. H. C. H. M. (1994). A simple automated test to measure exploratory and motor behavior of marmosets. Pharmacology, Biochemistry, \& Behaviour, 47, 879-881.

(Manuscript received December 18, 1998; revision accepted for publication November 1, 1999.) 